\title{
In vitro Antifungal Activities of Fluconazole, Camellia sinensis and Cydonia oblonga Leaf Extracts Against Candida Species Isolated from Blood Cultures
}

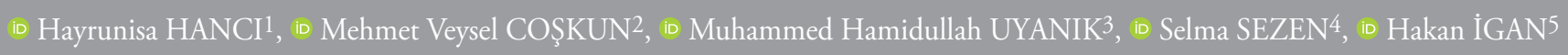

${ }^{1}$ Atatürk University Faculty of Pharmacy, Department of Pharmaceutical Microbiology, Erzurum, Turkey

${ }^{2}$ Gümüşhane State Hospital, Clinic of Medical Microbiology, Gümüşhane, Turkey

3Atatürk University Faculty of Medicine, Department of Medical Microbiology, Erzurum, Turkey

${ }^{4}$ Atatürk University Fculty of Science, Department of Biology, Erzurum, Turkey

sPalandöken State Hospital, Clinic of Medical Microbiology, Erzurum, Turkey

\section{ABSTRACT}

Objective: In this study we investigated in vitro antifungal activity of fluconazole, green tea (Camellia sinensis) and quince leaf (Cydonia oblonga) extracts in Candida strains isolated from blood cultures.

Methods: Fifty Candida spp were included to study. Camellia sinensis and Cydonia oblonga leaves collected from Rize and Erzurum/Tortum regions were prepared as an extract. Then stock solutions of the extracts and fluconazole powder obtained from the manufacturer were prepared for use in the Broth Microdilution (BMD) method according to Clinical and Laboratory Standards Institute (CLSI) M27 A3 recommendation. Fluconazole minimum inhibitory concentration (MIC) values obtained from BMD method were evaluated according to CLSI M27 A4 break points. MIC values obtained for Camellia sinensis and Cydonia oblonga were interpreted according to fluconazole break points since there is no break points in the literature.

Results: Of the 50 Candida spp. included in the study, 37 (74\%) were C. albicans while $13(26 \%)$ were non-albicans species. The most common isolated non-albicans species was C. parapsilosis (14\%). For all tested Candida strains $\mathrm{MIC}_{50}$ and $\mathrm{MIC}_{90}$ values for fluconazole were found to be $0.125 \mu \mathrm{g} / \mathrm{mL}-0.25 \mu \mathrm{g} / \mathrm{mL}$ while they were determined as $0.125 \mu \mathrm{g} / \mathrm{mL}-64 \mu \mathrm{g} / \mathrm{mL}$ and $0.125 \mu \mathrm{g} / \mathrm{mL}-0.125 \mu \mathrm{g} / \mathrm{mL}$ for green tea and quince leaves, respectively.

Conclusion: According to the low MIC values, it is seen that green tea and quince leaf are in vitro effective against Candida species. However, further extensive in vitro and in vivo studies should be done on the possibility that green tea and quince leaf can be used alternatively in the treatment of invasive Candida infections.

Keywords: Antifungal activity, Candida, fluconazole, green tea, quince leaf

\section{Introduction}

Invasive Candida infections are one of the major health problems with high mortality and morbidity rates, increasing hospitalization and cost of treatment (1). The incidence of candidemia cases is increased by malignancies, immunosuppressive diseases or treatments, use of broad-spectrum antibiotics and corticosteroids, aggressive chemotherapy and some major surgical procedures all over the world $(2,3)$. According to the Centers for Diseases Control and Prevention (CDC) and the National Healthcare

Address for Correspondence: Mehmet Veysel COŞKUN, Gümüşhane State Hospital, Clinic of Medical Microbiology, Gümüşhane, Turkey

Phone: +90 5434582833 E-mail: coskun.veysel@gmail.com ORCID ID: orcid.org/0000-0002-6626-9518

Cite this article as: Hancı H, Coşkun MV, Uyanık MH, Sezen S, İgan $\mathrm{H}$. In vitro Antifungal Activities of Fluconazole, Camellia sinensis and Cydonia oblonga Leaf Extracts Against Candida Species Isolated from Blood Cultures. Bezmialem Science 2019;7(2):107-12. 
Safety Network (NHSN), Candida species are the fourth most common sepsis cause in America and Europe (2,4-6).

Azoles are often used in the treatment of fungal infections with the advantage that they have less toxic effects than other antifungal agents. However, this situation recently has caused increased resistance to azole in fungal agents which prompts researchers to search for new antifungal agents, especially for resistant invasive Candida infections $(7,8)$.

Green tea (Camellia sinensis) and quince (Cydonia oblonga) leaf have been used for treatment of various infections in traditional medicine for centuries. And also there are various studies on antimicrobial activity of green tea and quince leaf in the literature most of which showed that green tea and quince leaf both have in vitro antimicrobial effects (9-12).

In this study, we investigated in vitro antifungal activity of green tea and quince leaf on Candida isolates obtained from blood cultures. The minimum inhibitory concentration (MIC) values of fluconazole were also evaluated for each isolates.

\section{Methods}

Candida strains: Fifty Candida spp. isolated from blood cultures (BACTEC 9000 System; Becton Dickinson) and sent to Medical Microbiology Laboratory between April 2013-December 2015 were included to the study. Repeated samples of the same patient were not included in the study. Chromogenic agar, tween 80 agar and related typing cards of VITEK 2 automatizated system (BioMerieux, France) were used to identify the isolated Candida species. Typed strains were stored at $-80^{\circ} \mathrm{C}$ with stock preparations as far as the planned schedule of the study. The strains were passaged twice in Saboraud Dextrose Agar (Oxoid, UK) after dissolved at room tempature to obtain appropriate culture. In the study, C. krusei ATCC 6258 and C. parapsilosis ATCC 22019 strains were used as control strains.

Preparation of extracts: Quince (Cydonia oblonga) and green tea (Camellia sinensis) leaves were collected from Tortum/Erzurum and Rize in their appropriate season. The dried and powdered leaves $(100 \mathrm{~g})$ of green tea and quince were extracted with $1 \mathrm{~L}$ of methanol using a Soxhlet extractor (SIGMA-ALDRICH, 322415) for $72 \mathrm{~h}$ at a temperature which was not exceeding the boiling point of the solvent. The extract was filtered using Whatman filter paper No.1 (Dassel, Germany) and then concentrated in vacuo at $40^{\circ} \mathrm{C}$ using a rotary evaporator (Buchi Labortechnic AG, Flawil, Switzerland). The plant extracts were then lyophilized and kept at $4^{\circ} \mathrm{C}$ until being tested (13).

Preparation of stock solutions: While fluconazole powder (Pfizer) was dissolved and diluted in sterile, pyrogen-free saline to a stock concentration of $256 \mu \mathrm{g} / \mathrm{mL}$ according to CLSI M27-A3 suggestions (14), prepared green tea and quince leaf extracts were both diluted to the concentration of $256 \mu \mathrm{g} / \mathrm{mL}$ as same as fluconazole since there is no standard MIC values for quince leaf and green tea extracts.
Broth Microdilution (BMD) method: To obtain MIC values of fluconazole, green tea and quince leaf for Candida strains, BMD method was applied by using L-glutamine, bicarbonate free, RPMI 1640 medium (Sigma Chemical Co., St Louis, Mo., USA) according to CLSI M27-A3 suggestions (14). This medium was used in the BMD test after adding $2 \%$ dextrose and adjusting $\mathrm{pH}$ to 7 with $0.165 \mathrm{M}$ morpholine-propanesulfonic acid (MOPS; Sigma). In the direction of this method two-fold decreasing serial dilutions of fluconazole, green tea and quince leaf were prepared in sterile, U-based, 96 well microplates by using stock solutions. Then Candida strains adjusted to 0.5 McFarland standard turbidity were added in each well of microplates except the last one. The last two wells were separated as sterilization control and reproduction control wells. Thus, the final concentration of fluconazole green tea and quince leaf were between range of $64 \mu \mathrm{g} / \mathrm{mL}$ to $0.125 \mu \mathrm{g} / \mathrm{mL}$. Plates were evaluated by two different investigators with naked eyes after 24-48 hours of incubation. The MIC value of the well with the smallest amount of drug with $50 \%$ or less reproduction relative to the reproduction control was recorded as MIC value. Fluconazole MIC values were evaluated according to the CLSI M27- S4 break points (15). Because of there is no standard MIC break points for quince leaf and green tea extracts, MIC values were evaluated by comparing with fluconazole break points.

\section{Statistical Analysis}

For analysis of the study data Statistical Package for Social Sciences (SPSS; v20.0) statistical program was used. The data were expressed as number, percentage, mean and standard deviation. Suitability to normal distribution of the data was investigated by the Kolmogorov-Simirnov test. The Kruskal Wallis test was used for the comparison of more than two groups of numerical data without normal distribution. The results were considered significant when $\mathrm{p}<0.05$.

\section{Results}

Total of 50 Candida spp (37 C. albicans, 7 C. parapsilosis, 3 C. tropicalis, 3 C. glabrata) were included in the study. Albicans species $(74 \%)$ were found to be more than non-albicans species (26\%). The most common isolated non-albicans species was $C$. parapsilosis (14\%).

Candida strains isolated from blood cultures of hospitalized patients in 11 different clinics in our hospital were included in the study. The clinics where these strains were most isolated were Anesthesia and Reanimation Intensive Care Unit (22\%), Internal Medicine Intensive Care Unit (16\%), Internal Medicine Hematology Service (12\%), Pediatric Intensive Care Unit (12\%) and Medical Oncology Service (10\%), respectively. Distribution of isolated Candida strains according to the services are shown in the Table 1.

For all tested Candida strains $\mathrm{MIC}_{50}$ and $\mathrm{MIC}_{90}$ values for fluconazole were found to be $0.125 \mu \mathrm{g} / \mathrm{mL}-0.25 \mu \mathrm{g} / \mathrm{mL}$ while they were determined as $0.125 \mu \mathrm{g} / \mathrm{mL}-64 \mu \mathrm{g} / \mathrm{mL}$ and $0.125 \mu \mathrm{g} /$ $\mathrm{mL}-0.125 \mu \mathrm{g} / \mathrm{mL}$ for green tea and quince leaves, respectively. 
Table 1. Distribution of isolated Candida strains according to the services

\begin{tabular}{|c|c|c|c|c|c|}
\hline Services & C.albicans & C.parapsilosis & C.tropicalis & C.glabrata & Total \\
\hline Anesthesia/Reanimation ICU* & 7 & 3 & 1 & - & 11 \\
\hline Internal Medicine ICU & 6 & 1 & - & 1 & 8 \\
\hline Pediatric ICU & 5 & - & 1 & - & 6 \\
\hline Medical Oncology & 5 & - & - & - & 5 \\
\hline Infectious Diseases & 2 & - & - & - & 2 \\
\hline Pediatric Hematology & 1 & 1 & - & - & 2 \\
\hline Cardiology ICU & 1 & - & - & - & 1 \\
\hline Brain Surgery ICU & 1 & - & - & - & 1 \\
\hline
\end{tabular}

Table 2. The results of $\mathrm{MIC}_{50}, \mathrm{MIK}_{90}$ and $\mathrm{MIC}_{\text {min-max }}$ obtained with BMD method against Candida strains for fluconazole, green tea and quince leaf $(\mu \mathrm{g} / \mathrm{mL})$

\begin{tabular}{|c|c|c|c|c|c|c|c|c|c|}
\hline \multirow[t]{2}{*}{ Strains } & \multicolumn{3}{|c|}{$\mathrm{MIC}_{50}$} & \multicolumn{3}{|c|}{$\mathrm{MIC}_{90}$} & \multicolumn{3}{|c|}{$M I C_{\min -\max }$} \\
\hline & Flu & GT & QL & Flu & GT & QL & Flu & GT & QL \\
\hline C.albicans (37) & 0.125 & 0.125 & 0.125 & 0.25 & 2 & 0.125 & $0.125-32$ & $0.125-64$ & $0.125-64$ \\
\hline C.tropicalis (3) & - & - & - & - & - & - & $0.125-0.25$ & $0.125-0.25$ & $0.125-0.25$ \\
\hline C.glabrata (3) & - & - & - & - & - & - & $0.125-0.25$ & $0.125-0.25$ & $0.125-0.25$ \\
\hline
\end{tabular}

There was no significant difference between fluconazole, green tea and quince leaf extract values obtained from Candida strains.

When MIC values were evaluated according to CLSI M27-S4 break points, all of the $C$. tropicalis and C. glabrata strains were susceptible; $2 C$. parapsilosis and $1 C$. albicans were resistant to fluconazole $(\mathrm{MIC}=32 \mu \mathrm{g} / \mathrm{mL})$. The $\mathrm{MIC}$ values of green tea and quince leaves for fluconazole resistant strains were $64 \mu \mathrm{g} /$ $\mathrm{mL}$. The results of $\mathrm{MIC}_{50}, \mathrm{MIK}_{90}$ and $\mathrm{MIC}$ range obtained with BMD method against Candida strains for fluconazole, green tea and quince leaf are shown in the Table 2.

\section{Discussion}

Candida spp are one of the important causes of nosocomial bloodstream infections. The incidence of Candida bloodstream infections have risen in the past 20 years worldwide. Generally $C$. albicans is the most frequently isolated Candida species in blood cultures, however in some studies non-albicans species have been isolated more frequently. The distribution of isolated species may vary by region. The most common non-albicans species isolated from blood cultures are C. parapsilosis, C. glabrata and C. tropicalis. It has been reported that $C$. krusei is the least frequently isolated species (16-19). In our study C. albicans was the most frequently isolated species (74\%) while C. parapsilosis was the most common among non-albicans species.

Today we use various antifungal agents, such as azoles, that raised significant progress in treatment of invasive Candida infections. Fluconazole is very often used with the advantage of its broad spectrum and low toxicity than others. Although in our study, fluconazole resistance was 6\% (2 C.parapsilosis and 1 C. albicans), some studies showed that azole resistance have increased recently because of common use (20-23). Due to this current case and inadequate antifungal treatment options, Candida bloodstream infections are still common extending the length of stay in hospitals and increasing the cost of care $(24,25)$. That makes researchers look for alternative antifungal agents. There are many plants with medical features. There is a widespread belief that medicinal plants are healthier and more harmless or safer than synthetic ones. These medicinal plants have a rich content that can be used to develop drugs. In recent years, studies on antifungal properties of some plants have been revealed (26-28).

Green tea is an easily accessible plant in Turkey. Previous studies have given positive results on antifungal activity of green tea. According to the results of the studies, in the future the green tea extracts may be considered as a therapeutic adjunct on oral 
Candida species $(10,29,30)$. In a study, it was demonstrated that green tea was found to be very effective on C. albicans, Streptococcus mutans and Lactobaclli spp (31). Yang and Jiang (32) have reported that tea polyphenols can inhibit mycelial growth and spore germination of Rhizopus stolonifer. Aladag et al. (33) demonstrated that the antifungal activity of green tea leaves may be closely correlated to catechin content which can vary due to different harvest time. In this study fresh, green tea leaves were harvested in May which was the most convenient time and the $\mathrm{MIC}_{50}$ and $\mathrm{MIC}_{90}$ values were found to be $0.125 \mu \mathrm{g} / \mathrm{mL}-64 \mu \mathrm{g} /$ $\mathrm{mL}$. According to these results, it is interpreted that green tea is in vitro effective on Candida strains isolated from blood culture.

Quince, which is the other plant we used in this study (Cydonia oblonga), belongs to the family Rosaceae and Turkey is one of the most important quince producers worldwide (34). Leaf, fruit and seed of quince have very important medicinal effects. In studies with quince, many useful features have been reported such as antibacterial, antioxidant and antiproliferative, antiinflammatory and anti-dysenteric activities. Furthermore, it has been reported that it can also be useful in cancer, bloodstream and skin diseases (27). Fattouch et al. (35) have studied with various parts of quince and reported that quince may be a useful adjuvant agent for the treatment of bacterial infections in addition to antibiotics. Alizadeh et al. (26) reported that the quince leaf's extracts can inhibit the growth of Aspergillus niger. However, there is no satisfactory research result on anticandidal properties of quince leaf in the literature. In this study, we have invastegated anticandidal effects of quince leaf's mehtanolic extracts on 50 Candida species. The $\mathrm{MIC}_{50}$ and $\mathrm{MIC}_{90}$ values were $0.125 \mu \mathrm{g} /$ $\mathrm{mL}-0.125 \mu \mathrm{g} / \mathrm{mL}$, respectively and these results indicated that quince leaf extracts have good in vitro anticandidal effects with very low MIC levels.

Although the $\mathrm{MIC}_{50}$ and $\mathrm{MIC}_{90}$ values of both green tea and quince leaf extracts were very low, the situation was different in fluconazole resistant strains. In our study, 2 C. parapsilosis and 1 C. albicans strains were resistant to fluconazole and fluconazole MIC values were $32 \mu \mathrm{g} / \mathrm{mL}$ for all of them. When the MIC values of green tea and quince leaf of these strains were examined, it was found that the MIC value was $64 \mu \mathrm{g} / \mathrm{mL}$ for these strains. Because of this result, it was thought that green tea and quince leaf were not effective in fluconazole resistant Candida strains.

There are various studies on the use of green tea and quince leaf for therapeutic purposes and their effects on the body. In some of these studies the distribution of green tea components were calculated in blood and urine after oral intake (36). These studies serve as guides to show the distribution of green tea to the part of the body that is infected. One of these studies showed that, a cup of Japanese green tea contained about $150 \mathrm{mg}$ of epigallocatechin and about $3.5 \mathrm{mg}$ of it excreted into the urine per cup of tea (37). There are also many studies showing the phenolic components of quince leaf and the therapeutic effects of these components on the body $(27,38,39)$. Though these studies include only oral use, they are hopeful that green tea and quince leaf contents can be used to develop different form of drugs.

\section{Study Limitations}

In this study, the phenolic profile of the green tea and quince leave extracts could not be analyzed. Since the study was conducted with Candida strains isolated from the blood culture samples which were sent to our laboratory in a spesificied time period, no preliminary statistical study was done in terms of the number and types of strains to be used in the study.

\section{Conclusion}

In addition to making contributions to the literature about the antifungal activity of green tea on Candida species, this is the first study directly conducted on the evaluation of antifungal activity of quince leaf extracts on Candida species isolated from blood culture. According to the low MIC values obtained from the study, it was observed that green tea and quince leaf extracts both have in vitro antifungal activity on Candida species. However, further extensive in vitro and in vivo studies should be undertaken whether green tea and quince leaf can be used in the treatment of invasive Candida infections.

\section{Ethics}

Ethics Committee Approval: This study was approved by the Ethics Committee of Faculty of Medicine of Ataturk University, dated 28.04.2016 and numbered 4/08.

Informed Consent: Written informed consent was not received due to the nature of this study.

Peer Review: Externally peer-reviewed.

\section{Authorship Contributions}

Concept: H.H., Design: H.H., M.V.C., S.Ş., Data Collection or Processing: H.H., M.V.C., Analysis or Interpretation: H.H., M.V.C., Literature Search: H.H., M.V.C., H.İ., Writing: H.H., M.V.C.

Conflict of Interest: No conflict of interest was declared by the authors.

Financial Disclosure: This study was supported by the Scientific Research Project of Ataturk University (Project number 2016/111).

\section{References}

1. Bassetti M, Righi E, Costa A, Fasce R, Molinari MP, Rosso R, et al. Epidemiological trends in nosocomial candidemia in intensive care. BMC Infect Dis 2006;6:1.

2. Wisplinghoff H, Bischoff T, Tallent SM, Seifert H, Wenzel RP, Edmond MB. Nosocomial bloodstream infections in US hospitals: analysis of 24, 179 cases from a prospective nationwide surveillance study. Clin Infect Dis 2004;39:309-17.

3. Yapar N. Epidemiology and risk factors for invasive candidiasis. Ther Clin Risk Manag 2014;10:95-105.

4. Pfaller MA, Diekema DJ. Epidemiology of invasive candidiasis: a persistent public health problem. Clin Microbiol Rev 2007;20:13363.

5. Sievert DM, Rick P, Edwards JR, Schneider A, Patel J, Srinivasan 
A, et al. National Healthcare Safety Network (NHSN) Team and Participating NHSN Facilities. Antimicrobial resistant pathogens associated with healthcare-associated infections: summary of data reported to the National Healthcare Safety Network at the Centers for Disease Control and Prevention, 2009-2010. Infect Control Hosp Epidemiol 2013;34:1-14.

6. Tortorano AM, Peman J, Bernhardt H, Klingspor L, Kibbler CC, Faure O, et al. Epidemiology of candidaemia in Europe: Results of 28-month European Confederation of Medical Mycology (ECMM) hospital-based surveillance study. Eur J Clin Microbiol Infect Dis 2004;23:317-22.

7. Oxman DA, Chow JK, Frendl G, Hadley S, Hershkovitz S, Ireland $\mathrm{P}$, et al. Candidaemia associated with decreased in vitro fluconazole susceptibility: is Candida speciation predictive of the susceptibility pattern? J. Antimicrob. Chemother 2010;65:1460-5.

8. Kim D, Hwang GY, Yoo G, Kim J, Uh Y. Trend of prevalence and antifungal drug resistance of candida species ssolated from candidemia patients at a tertiary care hospital during recent two decades. Ann Clin Microbiol 2017;20:53-62.

9. Taylor PW, Hamilton-Miller JM, Stapleton PD. Antimicrobial properties of green tea catechins. Food Sci Technol Bull 2005;2:7181.

10. Reygaert WC. The antimicrobial possibilities of green tea. Front Microbiol 2014;5:1-8.

11. Nasırı Semnanı S, Hajizadeh N, Alizadeh H. Antibacterial effects of aqueous and organic quince leaf extracts on gram-positive and gramnegative bacteria. Banats J Biotechnol 2017;8:54-61.

12. Camargo L.EA, Pedroso LS, Vendrame SC, Mainardes RM, Khalil NM. Antioxidant and antifungal activities of Camellia sinensis (L.) Kuntze leaves obtained by different forms of production. Braz J Biol 2016;76:428-34.

13. Gulluce M, Agar G, Baris O, Karadayi M, Orhan F, Sahin F. Mutagenic and Antimutagenic Effects of Hexane Extract of some Astragalus Species Grown in the Eastern Anatolia Region of Turkey. Phytother Res 2010;24:1014-8.

14. Clinical and Laboratory Standards Institute (CLSI). Reference Method for Broth Dilution Antifungal Susceptibility Testing of Yeasts; Approved Standard M27-A3. CLSI, Wayne PA, USA. 2008.

15. Clinical and Laboratory Standards Institute (CLSI). Reference Method for Broth Dilution Antifungal Susceptbility Testing of Yeasts; 4th Informational Supplement, M27-S4. CLSI, Wayne PA, USA. 2012.

16. Pfaller MA, Pappas PG, Wingard JR. Invasive fungal pathogens: current epidemiological trends. CID 2006;43:3-14.

17. Sanguinetti M, Posteraro B, Lass-Flörl C. Antifungal drug resistance among Candida species: mechanisms and clinical impact. Mycoses 2015;58:2-13.

18. Ozkaya E, Calıskan A, Kirisci O, Tumer S. Distribution and antifungal susceptibilities of Candida species ssolated from blood cultures at Kahramanmaraş Necip Fazıl City Hospital in the last three years. Türk Mikrobiyol Cem Derg 2016;46:63-68.

19. Etiz P, Kibar F, Ekenoğlu Y, Yaman A. Retrospective evaluation of distribution and antifungal susceptibilities of Candida species isolated from blood cultures. ANKEM Derg 2015;29:105-13.

20. Savci U, Yilmaz N. Distribution of Candida species isolated from various sample and antifungal resistance ratio. Turkish Journal of Clinics and Laboratory Turk J Clin Lab 2017;8:85-90.

21. Pinhati HMS, Casulari LA, Souza ACR, Siqueira RA, Damasceno CMG, Colombo AL. Outbreak of candidemia caused by fluconazole resistant Candida parapsilosis strains in an intensive care unit. BMC Infect Dis 2016;16:2-6.

22. Grossman NT, Pham CD, Cleveland AA, Lockhart SR. Molecular mechanisms of fluconazole resistance in Candida parapsilosis isolates from a U.S. surveillance system. Antimicrob Agents Chemother 2015;59:1030-7.

23. Whaley SG, Berkow EL, Rybak JM, Nishimoto AT, Barker KS, Rogers PD. Azole Antifungal resistance in Candida albicans and emerging non-albicans Candida species. Front Microbiol 2017;7:112.

24. Wisplinghoff H, Ebbers J, Geurtz L, Stefanik D, Major Y, Edmond $\mathrm{MB}$, et al. Nosocomial bloodstream infections due to Candida spp. in the USA: species distribution, clinical features and antifungal susceptibilities. Int J Antimicrob Agents 2014;43:78-81.

25. Garzillo C, Bagattini M, Bogdanović L, Di Popolo A, Dora Iula V, Catania MR, et al. Risk factors for Candida parapsilosis bloodstream infection in a neonatal intensive care unit: a case-control study. Ital J Pediatr 2017;43:2-9.

26. Alizadeh H, Rahnema M, Nasırı Semnanı S, Ajallı M. Synergistic antifungal effects of quince leaf's extracts and silver nanoparticles on Aspergillus niger. JABS 2014;8:10-3.

27. Sajid SM, Zubair M, Waqas M, Nawaz M, Ahmad Z. A Review on Quince (Cydonia oblonga): A Useful Medicinal Plant. Global Veterinaria 2015;14:517-524.

28. Gozubuyuk GS, Aktas E, Yigit N. An ancient plant Lawsonia inermis (henna): Determination of in vitro antifungal activity against dermatophytes species. J Mycol Med 2014;24:313-8.

29. Madhura MG, Shweta RD, Kumar BV, Savithri, Gajalakshmi S, Soumya BV. Antifungal effect of green tea extracts on oral Candida species: An in vitro study. J Adv Clin Res Insights 2016;3:1-4.

30. Antunes DP, Salvia AC, de Araújo RM, Di Nicoló R, Koga Ito CY, de Araujo MA. Effect of green tea extract and mouthwash without alcohol on Candida albicans biofilm on acrylic resin. Gerodontology 2014;32:291-5.

31. Thomas A, Thakur S, Habib R. Comparison of antimicrobial efficacy of green tea, garlic with lime, and sodium fluoride mouth rinses against Streptococcus mutans, Lactobacilli species, and Candida albicans in children: A randomized double-blind controlled clinical trial. Int J Clin Pediatr Dent 2017;10:234-9.

32. Yang X, Jiang X. Antifungal activity and mechanism of tea polyphenols against Rhizopus stolonifer. Biotechnol Lett 2015;37:1463-72.

33. Aladag H, Ercisli S, Yesil DZ, Gormez A, Yesil M. Antifungal activity of green tea leaves (Camellia sinensis L.) sampled in different harvest time. Phcog Mag 2009;5:437-40. 
34. Yuksel C, Mutaf F, Demirtas I, Ozturk G, Pektas M, Ergul A. Characterization of Anatolian traditional quince cultivars, based on microsatellite markers. GMR 2013;12:5880-8.

35. Fattouch S, Caboni P, Coroneo V, Tuberoso CIG, Angioni A, Dessi S, et al. Antimicrobial activity of tunisian quince (Cydonia oblonga Miller) pulp and peel polyphenolic extracts. J Agric Food Chem 2007;55:963-9.

36. Reygaert WC. The antimicrobial possibilities of green tea. Front Microbiol 2014;5:434.
37. Reygaert W, Jusufi I. Green tea as an effective antimicrobial for urinary tract infections caused by Escherichia coli. Front. Microbiol 2013;4:162.

38. Oliveira AP, Pereira JA, Andrade PB, Valentão P, Seabra RM, Silva BM. Phenolic Profile of Cydonia oblonga Miller Leaves. Journal of Agricultural and Food Chemistry 2007;55:7926-30.

39. Sabir S, Qureshi R, Arshad M, Amjad MS, Fatima S, Masood M, et al. Pharmacognostic and clinical aspects of Cydonia oblonga: A review. Asian Pac J Trop Dis 2015;5:850-5. 